\title{
ORIENTE Y OCCIDENTE: DOS MODELOS DE ENSEÑANZA DEL DERECHO ROMANO
}

\author{
Alfonso AGUDo RUIZ \\ CATEDRÁTICO DE DERECHO ROMANO \\ UNIVERSIDAD DE LA RIOJA
}

\begin{abstract}
SUMARIO: I. Comienzos de la enseñanza del derecho. II. Enseñanza del derecho durante el principado. III. La enseñanza del Derecho en la Monarquía absoluta o Dominado. IV. La enseñanza del Derecho en época de Justiniano. V. Bibliografía. V.r. Fuentes. V.2 Revistas y colecciones de escritos.
\end{abstract}

RESUMEN: El presente estudio pretende dar una visión general de la enseñanza del Derecho romano en sus catorce siglos de historia, sin olvidar los aspectos políticos, sociales y económicos que condicionarán la creación y evolución del Derecho y, consiguientemente, su enseñanza. Este largo proceso se verá condicionado por la distinta visión política que sobre la enseñanza del Derecho tendrá el poder imperial de Occidente y de Oriente para satisfacer las necesidades de su administración imperial civil y judicial.

\begin{abstract}
The present investigation tries to give a general view of the teaching in Roman law during fourteen centuries of history, without forgetting the political, social and economic sides, which will determine the creation and evolution of the Law and consequently its teaching. This long process will be determined by the different political views of the teaching of Law, which the eastern and western imperial power has in order to satisfy the needs of its civil and judicial imperial administration.
\end{abstract}

PALABRAS CLAVES: Derecho; juristas; Oriente-Occidente; Justiniano-plan de estudios.

KEYWORDS: Law; jurists; East - west; Justiniano-study plan.

\section{Los comienzos de la enseñanza del Derecho}

En Roma, derecho y política son dos fenómenos que se encuentran unidos inseparablemente. La concepción política imperante en cada momento histórico, determinará la creación del derecho y, consiguientemente su enseñanza. El largo proceso de la enseñanza del Derecho romano se inicia hacia la mitad del siglo VIII a.C. y culmina con la muerte de un emperador de Oriente llamado Justiniano, en el siglo VI, es decir, durante un período de catorce siglos.

La distinción entre la parte oriental y la parte occidental del Imperio iniciada por Diocleciano fue, desde el principio, más que una división política-administrativa, ya que corresponde a un modo distinto de entender y proteger la cultura jurídica que había sido desde sus orígenes patrimonio exclusivo de Occidente. La historia de la enseñanza del Derecho romano, en la parte occidental, es la historia de la jurisprudencia y de sus protagonistas, los juristas, mientras que en la parte oriental, se corresponde con su 
institucionalización en escuelas o universidades, bajo el control directo del poder político, siendo impartida por profesores-funcionarios.

En Oriente, a diferencia de Occidente, se dieron las condiciones adecuadas que propiciaron un rico florecimiento del Derecho romano a través de su enseñanza en las escuelas o universidades de Derecho. De entre todas destacan las Escuelas de Berito y de Constantinopla que produjeron una época de renacimiento brillante de la ciencia jurídica en los siglos V y VI, con la consiguiente conservación de las obras de los juristas clásicos en su texto integral para la posteridad y, tan útil habría de resultar para el desarrollo de la ciencia jurídica europea, difundida más allá de los límites continentales.

Para analizar el largo proceso de la enseñanza del Derecho romano, es necesario tener en cuenta las distintas etapas político-constitucionales que conoció Roma a lo largo de su historia, así como sus distintas fuentes de producción y de conocimiento del Derecho.

Durante la Monarquía, el conocimiento, interpretación, adaptación y aplicación del derecho privado fue monopolio del Colegio pontifical. Los pontífices formaban el más importante de los cuatro colegios sacerdotales, tenían competencia en cuestiones de derecho sagrado y de derecho civil por la íntima conexión del derecho con la religión. Ello permitirá una permeabilidad recíproca que evitará conflictos entre el poder político y el poder religioso; cuando se separen ius y fas ello representará una conquista de la madurez de la jurisprudencia romana. Como afirma Fernández de Buján, A.', se consideraban depositarios de la tradición, conocedores del calendario judicial ${ }^{2}$ y de los formalismos de los actos procesales y negociales que guardaban celosamente. Ahora bien, continua el citado autor, la interpretación del Derecho no se entendía realizada por los pontífices en atención a la voluntad de los dioses, sino que tenía su propia técnica, su propia lógica y su propia fundamentación conservadas por escrito y en secreto en los libri pontificales. En este sentido, puede afirmarse la existencia, en el propio ámbito de actuación del Colegio pontifical, de una diferenciación progresiva entre normas jurídicas relativas a las relaciones entre las personas y con la comunidad y normas sacras que contemplan las relaciones entre personas y los dioses.

Por su carácter aristocrático, las respuestas de los pontífices tienen un estilo seco y autoritario, sin un razonamiento o argumento que justifique los criterios seguidos. El procedimiento para su elaboración era racional, pero el carisma del Colegio bastaba para fundar la decisión y una explicación de los motivos la habría disminuido. El responsum emitido era anotado en los commentarii Pontificum, para que los componentes del Colegio pudiesen consultarlos ante nuevos casos.

En este ambiente de secretismo, no puede hablarse todavía de enseñanza del Derecho, en el sentido de que cualquier ciudadano pueda acceder libremente a su conocimiento. Dicho conocimiento era gestionado de modo monopolístico para mantener y defender la superioridad social y política de la clase gobernante. Coherente con este carácter reservado, no se conoce una literatura jurisprudencial de origen sacerdotal. El misterio viene administrado por los pontífices como un instrumento de poder. Por tanto, su conocimiento y enseñanza, como afirma $\mathrm{Kunkel}^{3}$, sólo fue accesible a sus miembros y únicamente en su seno se transmitieron de generación en generación los métodos de interpretación y aplicación del Derecho, que ellos habían desarrollado y practicado.

\footnotetext{
IFERNÁNDEZ DE BUJÁN, A., Derecho Público Romano. Recepción, Jurisdicción y Arbitraje (Madrid 2008) p. I35

En general sobre el calendario romano, vid. AGUDO RUIZ, La enseñanza del Derecho en Roma (LogroñoMadrid I999) p. 22 nt. I8.

${ }^{3}$ KUNKEL, Linee di storia giuridica romana, trad. ital. De Tullio e Bianca Spagnuolo Vigorita (Napoli i973) p. I30; ID. Historia del Derecho romano, trad. esp. Miquel (Barcelona I989) p. Io6.
} 
A partir del siglo $\mathrm{V}$ hasta el siglo III a. C. se producen distintos hitos que van a poner fin gradualmente a la posición de monopolio jurídico del Colegio pontifical. El punto de partida del proceso de laicización del derecho en la civitas se inicia con la publicación de la Ley de las XII Tablas a mediados del siglo V a.C.; sin embargo, ello no debió implicar un inmediato cambio de su situación preeminente, según las palabras de Pomponio: «et fere populus annis prope centum hac consuetudine usus est» ${ }^{4}$. Es natural, pues, dejando aparte que precisamente la ley no contenía los formularios elaborados por los pontífices, el saber laico todavía no se encontraba en un nivel suficiente como para poder interpretar y aplicar de manera continua y regularmente las disposiciones decemvirales.

Otro hito fundamental sería la publicación por Cneo Flavio del denominado «ius civile Flavianum», constituido por un calendario judicial y un conjunto de fórmulas procesales, compuestas por Apio Claudio para poner fin al patrimonio exclusivo del secreto pontifical. Este proceder celebrado por el pueblo convirtió a Cneo Flavio, a pesar de su humilde condición, en edil curul en el año 304 a.C. Por su parte Apio Claudio publicaría un pequeño tratado titulado «De usurpationibus», que debe identificarse con el «ius Flavianum ${ }^{5}$. Este hecho marca el inicio de la apertura de la jurisprudencia pontifical de una manera lenta, gradual, sin cambios revolucionarios. Desde este punto de vista, la importancia de la acción de Apio Claudio y de su escriba Cneo Flavio, radica en haber recogido por escrito las complejas fórmulas orales, lo que acrecentaba la certeza del derecho en una medida como no sucedía desde las XII Tablas, y abría así el camino de la interpretatio a las futuras generaciones de juristas.

En esta línea de superación del secretismo de la jurisprudencia pontifical se ha venido presentando a Tiberio Coruncanio, cónsul en el 280 a.C., hombre de gran cultura ${ }^{6}$ y el primer plebeyo que accede a desempeñar el cargo de Pontífice Máximo en el año 254 a.C., dando respuestas, sobre cuestiones de derecho, en público. En base a esta forma peculiar de desarrollar su actividad jurídica, Pomponio le considera como el primer docente de la historia del Derecho romano ${ }^{7}$. La gran novedad del proceder de Tiberio Coruncanio no radica simplemente en haber admitido la presencia de oyentes en el lugar en el que enunciaba sus pareceres, ya que este mismo hecho no habría sido tan destacable, sino en desvelar las motivaciones jurídicas que le habían llevado a dar tal o cual solución al caso concreto planteado, transmitiendo a los oyentes sus conocimientos y empezando aquellos a percibir el Derecho como una técnica. La distinción hecha por Pomponio entre la actividad del publice profiteri, instaurada por Coruncanio, y aquella de los antiguos sacerdotes -in latenti civile retinere-, basta por sí misma para resaltar la importancia de la innovación introducida en el ejercicio de la ciencia jurídica: al secretismo de las antiguas consultationes y a la consiguiente falta de una enseñanza del Derecho, Coruncanio contrapone el ejercicio de una ciencia basada en el publice respondere que comporta un automático publice docere.

Sin embargo, en este momento histórico ciertamente no se puede afirmar que existiese una enseñanza científica del Derecho, puesto que el propio Derecho no pasaba de ser un arte o práctica, y la enseñanza no podía ser científica, por falta de principios teóricos y ausencia de una ordenación sistemática, tampoco era regular puesto que, como se deduce de las palabras de Pomponio, Tiberio Coruncanio se limitaba a enseñar el Derecho a los que a él acudían deseosos de aprender ${ }^{8}$. No se trata de una enseñanza regular y sistemática, sino de una enseñanza eminentemente práctica, directa «de la boca del maestro a los oídos del

\footnotetext{
${ }^{4}$ D. I, 2, 2, 6 (Pomp. lib. sin. Ench.).

${ }^{5}$ Sobre el tema, vid. AGUDO RUIZ, La enseñanza, cit., pp. 24 ss.

${ }^{6}$ Coruncanio era un profundo conocedor de la cultura griega, cfr. Cicerón, De orat., 3, I5, 56.

${ }^{7}$ D. I, 2, 2, 35 (Pomp. lib. sing. Ench.).

${ }^{8}$ Cfr. KÜBLER, s.v. Rechtsunterricht, en P. W. I A I (Stuttgart I9I4) p. 394; HERNÁNDEZ TEJERO, Algunas consideraciones sobre la enseñanza del Derecho en Roma desde los orígenes hasta Justiniano, en Revista de la Facultad de Derecho, I4 (Madrid I944) p. I38.
} 
discípulo», enseñanza que se mantendrá hasta el final de la jurisprudencia. Como afirma Fernández de Buján, $\mathrm{A}^{9}$, es probable que sea entonces cuando comienza la enseñanza no reglada del Derecho y no tanto del contenido de la norma jurídica, sino de la técnica de argumentación, de la fundamentación, de la lógica jurídica, del debate de ideas en el foro (disputatio fori), que tenía un carácter eminentemente práctico. Se trataba de razonar entre el maestro-jurista experimentado y sus discípulos, aspirantes al conocimiento del Derecho, sobre casos concretos reales o imaginarios, a los cuales había que dar la solución más justa posible con arreglo al Derecho vigente, o proponer una regulación diferente a la vista de la nueva realidad social o del cambio de concepción sobre la justicia de la solución prevista.

Papel destacado ocupa en la enseñanza del Derecho la familia romana. Todos los historiadores están de acuerdo en subrayar el insustituible papel que cumple la familia en la antigua educación romana. La familia es el medio natural donde debe crecer y formarse el niño. La educación recibida por el niño en el seno de la domus es una educación eminentemente moral, más que intelectual. Lo esencial es formar la conciencia del niño o del adolescente, inculcarle un sistema rígido de valores morales, de reflejos seguros, un estilo de vida que conviertan al niño en un ciudadano ejemplar ${ }^{\mathrm{ro}}$.

En la persecución de este objetivo aparecen empeñados los responsables de la familia romana. Durante la República, la madre asume la educación del niño varón durante sus primeros siete años de vida. Ella será la encargada de dirigir y corregir todas las manifestaciones del niño, en los juegos, en los descansos o en los estudios, y ello teniendo siempre muy presente que el niño de hoy es el hombre que mañana deberá cumplir con toda honradez sus deberes cívicos ${ }^{\text {II }}$. La educación que transmite la madre a su hijo es una educación eminentemente moral, modos de comportamiento, ideales patrios y familiares, nociones prácticas, históricas y culturales, respeto incondicionado a la ley, etc. Toda esta transmisión de valores sociales y morales fundamentales se realiza oralmente y, por consiguiente, fundados sobre la memoria colectiva, o mejor dicho, sobre la confluencia de diversas memorias -individual, familiar, gentilicia- en la memoria colectiva ${ }^{\mathrm{I2}}$.

El paterfamilias romano, consciente de su posición hegemónica dentro del grupo familiar -qui in domo dominium habet-asume con el mayor cuidado y esmero este papel de educador. Era una educación para la vida y por la vida, buscando en el niño la salud física, el vigor intelectual y la firmeza moral. Se pretendía hacer un hombre que se desenvolviera ágilmente en la vida, imbuido de principios morales, respetuoso en materia de religión, de conducta intachable y cabal, sobrio y templado, duro y resistente en las fatigas ${ }^{13}$. Baste recordar lo que hizo M. Catón con su propio hijo M. Catón Liciniano, el cual cuando ya empezó a tener alguna comprensión, él mismo tomó a su cuidado el enseñarle las primeras letras, a pesar de tener un esclavo llamado Quilón, bien educado y ejercitado en esta enseñanza. Fue su maestro de gramática, de derecho, de gimnasia, de esgrima, de equitación, de boxeo y de natación. Incluso compuso para su hijo una historia de Roma para que aprendiese a conocer mejor el pasado de su patria ${ }^{\mathrm{I} 4}$.

La instrucción doméstica constituye un privilegio de las clases más ricas y conservadoras de la República. Se trata de un tipo de educación patriarcal que tiende a consolidar y perpetuar determinados privilegios socio-políticos y económicos de la clase

\footnotetext{
${ }^{9}$ FERNÁNDEZ DE BUjÁN, A., Derecho, cit., p. 136.

${ }^{\text {10 }}$ MARROU, Historia de la educación en la antigüedad, trad. esp. De Borja de Quiroga (Madrid I985) p. 306.

"Tácito, Dial. orat. 28, 6.

${ }^{\mathrm{r} 2}$ Sobre la complejidad de la formación de esta memoria colectiva y de su transmisión y perpetuación, vid. DETIENNE, L'invenzione della mitología (Torino I983).

${ }^{13}$ Cfr. GUILLÉN, Urbs Roma. Vida y costumbres de los romanos (Salamanca I977) p. I93.

${ }^{14}$ M. Cato, 20, 5, 6 y 7.
} 
gobernante. Esta educación familiar e íntima se mantiene durante los primeros tiempos del Principado, siendo a partir de Vespasiano cuando se produce una profunda transformación: la aristocrática cultura familiar y privada viene sustituida por una enseñanza pública, provocando el declinar de la nobilitas de origen republicano.

En el último siglo de la República, el estudio y la enseñanza del Derecho adquieren una cierta autonomía residual y a efectos instrumentales de la oratoria forense como materia de la enseñanza superior impartida en las escuelas latinas de retórica que se inician sobre el modelo griego. Con este tipo de formación se pretendía cultivar únicamente la habilidad retórica, no es el conocimiento del Derecho lo que se cuida, sino la preparación para los tribunales, en un sistema judicial donde primaba el principio de la oralidad y se desarrollaba ante jueces no técnicos en derecho.

La jurisprudencia laica se consolida en el siglo III a.C. Sin embargo, todavía el conocimiento del Derecho no puede considerarse como «popular», en el sentido de que sea accesible a todos los ciudadanos. Sigue siendo una ciencia fundamentalmente aristocrática. La nueva clase de la nobilitas detentará el poder político, y por ende, también el poder cultural. Las actividades intelectuales socialmente más relevantes, como la jurídica, serán monopolizadas por la nueva oligarquía dominante.

Aquellos jóvenes que habían terminado sus estudios de retórica podían adquirir un conocimiento más profundo del Derecho mediante el denominado tirocinium fori. Como afirman García Garrido y Francisco Eugenio ${ }^{\mathrm{I5}}$, en el siglo III a.C. se convirtió en costumbre que aquellos muchachos nacidos libres, cuyos padres podían permitírselo, emprendieran, después de los liberalia, un período de preparación, relativamente informal, de la vida política y jurídica. El aprendizaje del Derecho se hacía en una situación de acompañante de un jurista experto y, naturalmente, al margen de toda suerte de escuelas. Era un aprendizaje esencialmente práctico -nada de teorías, nada de conceptos generales-, completamente personal, personalizado, personalista, y absolutamente informal -sin programa, sin calendario, sin escuela-.

Para Schulz ${ }^{\mathrm{r} 6}$, no hay una propedéutica jurídica, ni una introducción filosófica o histórica al Derecho. El jurista no discute con su discípulo conceptos fundamentales como la justicia, el derecho o la ciencia jurídica. El Derecho se aprende viviéndolo, en contacto con la práctica y con la tradición profesional, «se aprende a combatir sobre el campo de batalla». En este sentido, Cicerón ${ }^{\text {17 }}$ describe cómo realizó sus estudios jurídicos bajo la dirección de Q. Mucio Augur y Q. Mucio pontífice. En la escuela se aprendía una noción elemental del derecho y después uno se incorporaba al círculo de un jurisconsulto, con el que vivía y al que acompañaba cuando daba respuestas en público, o asistía a los procesos. El discípulo tomaba nota de las respuestas y consejos que daba su maestro y su mejor escuela era la práctica.

El desarrollo de una jurisprudencia no sacerdotal consolidada en el siglo III a.C. no interrumpe la estrecha relación entre el Colegio Pontifical y el ius civile, prolongándose hasta finales de la época del Principado. El arquetipo del pontífice habría condicionado siempre, de un modo $u$ otro, el modelo del jurista romano que se habría sentido continuador de la arcaica scientia iuris. La actividad del Colegio Pontifical hubo de sufrir la competencia de aquellos individuos de la nobilitas que, sintiéndose atraídos por los estudios jurídicos, quisieron ganar fama y popularidad aconsejando a los particulares, apoyados, exclusivamente, en su prestigio personal.

\footnotetext{
${ }^{15}$ GARCÍA GARRIDO y FRANCISCO EUGENIO, Estudios de Derecho $y$ Formación del Jurista (Madrid I988) pp. $40 \mathrm{~s}$.

${ }^{16}$ SCHULZ, Storia della Giurisprudenza romana, trad. ital. De Nocera (Firenze I968) pp. Iog ss.

${ }^{17}$ Cicerón, De amicit. I, I; Brut. 83, 306; De leg. I, 4, I3.
} 
El conocimiento del Derecho sigue siendo una ciencia fudamentalmente aristocrática $^{\mathrm{I} 8}$. La actividad de los juristas laicos se desplegó en aquellas tres direcciones que con anterioridad lo había hecho la jurisprudencia pontifical ${ }^{\text {19 }}$ y que vienen expresadas mediante los tres verbos: respondere, cavere y agere ${ }^{20}$.

Mediante los responsa, contestan a las cuestiones o dudas que se les hacen sobre casos reales y debatidos por particulares, magistrados y jueces, que redactan en cartas dirigidas al juez, o exponían verbalmente al que les consultaba, el cual los recogía por escrito en un documento autorizado por testigos. Es la actividad más importante de los juristas y lo siguió siendo hasta el final de la jurisprudencia clásica, es decir, durante un período de unos cinco siglos y fue precisamente a través de esta función cómo se desarrolla la labor de interpretatio que tanta importancia tuvo en la evolución del Derecho romano.

La actividad del cavere consiste en señalar a las partes el tecnicismo y el formalismo de los negocios jurídicos aptos para lograr los distintos resultados prácticos perseguidos por las partes intervinientes. En este sentido, cavere, hace referencia a las garantías o cautelas que se podían introducir en los negocios para mayor seguridad en su cumplimiento. Los romanos designan esta actividad con el nombre de jurisprudencia cautelar.

Por último, mediante el agere los juristas intervienen en la dirección del procedimiento, facilitando a la parte los términos precisos en que había de plantear el litigio en las acciones de la ley, o suministrándole un borrador de la fórmula que debía redactarse en el procedimiento formulario.

En íntima relación con la actividad dictaminatoria de los juristas se encuentra la enseñanza del Derecho, que en la época a que nos estamos refiriendo, tenía un carácter eminentemente práctico, no existe una enseñanza formalizada, ni una escuela de Derecho: los discípulos rodeaban al jurista que dictaminaba; oían sus respuestas y se les permitía explicar con él razones en pro y en contra. Cabe hablar, por tanto, de una simbiosis entre el respondere y el docere, constituyendo el dictamen el germen de la verdadera esencia de la enseñanza del Derecho. Es así como va surgiendo una actividad peculiar en la civitas: la enseñanza del Derecho, al cultivo de la cual se dedican los ciudadanos de la más alta condición social.

Este primer método docente denominado audire, por hacer referencia a los primeros alumnos, históricamente hablando, los llamados auditores, sería en sus líneas esenciales el método adoptado a finales de la República por el gran jurista Q. Mucio Escévola, según el parágrafo 42 del fragmento II del título II del libro I del Digesto, donde nos dice Pomponio refiriéndose a Mucio: «Mucii auditores fuerunt complures, sed praecipuae auctoritatis Aquilius Gallus, Balbus Lucilius, Sextus Papirius, Caius Iuventius...» Mucio, sigue la práctica tradicional iniciada por la jurisprudencia pontifical de admitir la presencia de oyentes que aprendían de viva voz el arte de responder.

Junto al tradicional audire, existen otros dos métodos más, el instituere y el instruere, de los cuales, según Pomponio en el parágrafo 44 del fragmento II del título II del libro I del Digesto, se habría beneficiado Servicio Sulpicio Rufo, maestro del Derecho que creó una verdadera escuela: la serviana, entre cuyos discípulos destacan Aufidio Namusa, Alfeno Varo y Aulo Ofilio. El instituere, de donde deriva el término institutiones, denominación de los libros de introducción que estudiaban los que se iniciaban en el

\footnotetext{
${ }^{18}$ Esta cuestión ha sido puesta de relieve magistralmente por Cicerón, Mur. II, 25; 12, 26.

${ }^{19}$ Para las diferencias entre la actividad de los juristas laicos y la jurisprudencia pontifical, vid. CANNATA, Historia de la ciencia jurídica europea, trad. esp. de Gutiérrez Masson (Madrid I996) pp. 30 ss.

${ }^{20}$ Cicerón, De orat. I, 4I, I4I; I, 48, 2I2; Mur. 9, I, 45; Top. I7.
} 
conocimiento jurídico, consiste en cimentar con una preparación elemental, metódica y teórica, la formación del jurista. El instruere, de ahí instructiones o esquemas o formularios o ejemplos, que pudieron quizá ser los instrumentos y maneras de realizar una formación práctica y acabada, hace referencia a una enseñanza más perfeccionada, al último estadio en el proceso de formación del jurista, esto es, habituar a los discípulos a la práctica forense y a la redacción de escritos jurídicos.

\section{La enseñanza del Derecho durante el Principado}

En el primer período del Principado la jurisprudencia romana cristaliza en las dos famosas sectae o scholae: sabinianos y proculeyanos, cuya adscripción por parte de los juristas a una u otra debió obedecer a simples razones de simpatía personal, a la tradición familiar o a la pietas del discípulo frente a la persona y opiniones del maestro ${ }^{2 \mathrm{I}}$. Como afirma Kunkel ${ }^{22}$, ambas escuelas no eran centros de enseñanza, aunque es fácil que la formación de los discípulos tuviera lugar, en su mayor parte, en la comunión de la escuela. Las escuelas eran agrupaciones de juristas ya hechos y de juristas en ciernes, cultivando cada una de ellas una determinada tradición de opiniones enseñadas. En este mismo sentido, afirma García Garrido que se trataría de grupos o círculos de jurisconsultos, unidos en torno a prestigiosas personalidades, como Labeón y Casio o Sabino, que seguían una cierta tradición en las respuestas y opiniones. Estas escuelas atraerían a numerosos discípulos y es probable que en ellas encontrasen medios de enseñanza y formación.

A partir de Augusto, como complemento a la distinción del ius publice respondendi otorgado a los jurisconsultos más destacados, surgen las escuelas públicas de Derecho, que Aulo Gelio designa con el nombre de stationes ius publice docentium aut respondentium.

No cabe pensar que estemos ante escuelas o universidades estatales como las que encontramos funcionando en el Bajo Imperio: Berito o Constantinopla. Realizan una cierta actividad docente específicamente jurídica y desarrollada fuera del esquema de relación individualizada. Como afirman García Garrido y Francisco Eugenio ${ }^{23}$, no debe pensarse por eso que en tales Stationes se desarrollase una enseñanza formalizada del derecho, una enseñanza propia y verdadera de un centro docente. Nada de eso. Era una enseñanza sin la organización convencional de un plan de estudios, un programa, un horario, ni menos unos alumnos matriculados que al fin de sus estudios habrían de obtener el correspondiente diploma; tales alumnos eran simplemente unos oyentes del jurista, oficialmente reconocido, autorizado, para responder y enseñar, eran unos meros auditores. No obstante, como opina Guarino ${ }^{24}$, estas escuelas no debieron absorber toda la enseñanza del Derecho en la Roma clásica, al menos durante el primer siglo del Imperio, sino que todavía se mantendría el sistema docente republicano de asistir a las consultas de los juristas en su propia casa.

¿Dónde estaban ubicadas las escuelas jurídicas? Las stationes o auditoria ${ }^{25}$ estaban generalmente situadas en las proximidades de los templos y contaban con bibliotecas sobre la materia jurídica. Parece que la primera escuela data de tiempos de Augusto. Augusto, tras la batalla de Actium, en el 3I a.C., mandó construir un templo en el Monte Palatino dedicado al dios Apolo. Junto a este templo se construyó una de las más famosas bibliotecas

\footnotetext{
${ }^{21}$ Sobre el origen y caracteres distintivos de ambas escuelas, vid. AGUDO RUIZ, La enseñanza, cit., pp. 55 ss.

${ }^{22}$ KUNKEL, Linee, cit., pp. I34 S., I54 SS.; ID. Historia, cit., p. I23.

${ }^{23}$ GARCÍA GARRIDO y FRANCISCO EUGENIO, Estudios, cit., p. 45. Cfr. CHURRUCA, Introducción, cit., p. I56.

${ }^{24}$ GUARINO, Storia del diritto romano (Napoli i994) p. 459.

${ }^{25}$ Gell. I3, I3, I; D. 23, 3, 78, 4; D. 40, I5, I, 4; D. I2, I, 40.
} 
de Roma para el estudio del Derecho y las artes liberales denominada biblioteca ad Apollinis $^{26}$. Pero entre todas ellas, destaca el Athenaeum de Adriano. De inspiración helénica, se trata de un amplio auditórium en forma de anfiteatro, erigido probablemente sobre el Capitolio y destinado a pronunciar conferencias y lecciones públicas los retóricos, filósofos y juristas. Respecto a la enseñanza jurídica creemos que no se trata en su origen de un centro público de enseñanza superior ${ }^{27}$, tal y como los encontraremos en el período postclásico, aunque quizá sea el precedente de la famosa Universidad de Roma.

Por otra parte, como afirma Hernández Tejero ${ }^{28}$, tampoco sabemos a ciencia cierta, en esta época, si un alumno tenía o no varios profesores. Sin embargo, en la época final de la República unas veces tenemos la indicación de un jurista formado con varios maestros, como ocurre con Servio, mientras que otros parecen haberse formado con un solo maestro. Lo que no podemos ni siquiera conjeturar es el número de alumnos que tenía cada profesor ni el tiempo que consagraba a la enseñanza. Sabemos que Labeón dedicaba seis meses al año a las tareas docentes en Roma ${ }^{29}$.

Nada sabemos en cuanto a la organización y metodología utilizada en estas escuelas. Cabe pensar que fuera una metodología basada en el respondere-docere. Los juristas seguirían realizando su actividad esencial consistente en dar respuestas a las cuestiones jurídicas planteadas por los particulares, ahora en las stationes o lugares públicos, donde simultáneamente daban también enseñanzas jurídicas.

A partir de la época de Trajano, y sobre todo de Adriano (II7-I38), el hecho de que la actividad de los grandes juristas quedase absorbida por el servicio en los altos puestos de la administración imperial y del Consilium Principis los retrajo probablemente de una actividad académica directa en las escuelas, que queda en manos de los maestros de derecho -magistri iuris-, que constituyen una figura profesional distinta y de menor prestigio social a la del jurista. Para Fernández Barreiro ${ }^{30}$, este proceso se encuentra relacionado con las crecientes necesidades funcionariales de la organización de la administración civil imperial. El conjunto de los funcionarios de la administración imperial y los prácticos del derecho reciben su formación jurídica elemental en las escuelas de retórica, y en otras modalidades de tipo más práctico, sin que lleguen a constituir formas de enseñanza estable ni organizada del derecho, a un nivel, naturalmente, distinto del que era propio de la metodología jurisprudencial.

En esta línea cabe afirmar que la actividad jurisprudencial nunca se popularizó en Roma. Como ha observado Cannata ${ }^{3 \mathrm{I}}$, la jurisprudencia era una ciencia de elite, los juristas eran muy poco numerosos y celosos de su habilidad profesional, cuya salvaguardia les conducía a conservar el carácter privado de su enseñanza; de hecho, su método hacía impensable una enseñanza que no estuviera ligada a su actividad práctica de consultores. La

\footnotetext{
${ }^{26}$ Juv. I, I28: bibliothecam iuris civilis...in templo Apollinis dedicavit Augustus...iuxta Apollinis templum iuris peritus sedebat et tractabat. Cfr. HERNÁNDEZ TEJERO, La enseñanza, cit., p. I52; LIEBS, Rechtsschulen und Rechtsunterricht in Prinzipat, en Aufstieg und Niedergang der römischen Welt, II, I5 (Berlin-New York I976) pp. 236 ss.; GARCÍA GARRIDO y FRANCISCO EUGENIO, Estudios, cit., p. 46 nt. 22; PESANDO, Libri e biblioteche. Vita e costumi dei romani antichi, I7 (Roma I994) pp. $58 \mathrm{ss.}$

${ }^{27}$ Cfr. MAZZARINO, Prima cátedra, en Melanges d'Archeologie et d'Histoire offerts'a Ander Piganiol (Paris I966) pp. I659 ss.; DELL'ORO, Athenaeum e Diritto in Roma, en Testimonium Amicitiae (Milano I992) pp. I47 ss.

${ }^{28}$ HERNÁNDEZ TEJERO, La enseñanza, cit., pp. I48 s.

${ }^{29}$ D. I, 2, 2, 47 .

${ }^{30}$ FERNÁNDEZ BARREIRO, El factor jurisprudencial como elemento de identidad de la cultura jurídica europea (Granada I998) pp. 5I ss.

${ }^{31}$ CANNATA, Historia, cit., pp. 8I s.
} 
lista confeccionada por Lenel de los juristas que, desde Sexto Elio a Hermogeniano, nos son conocidos como autores de obras jurídicas, no menciona más que noventa y dos juristas.

Durante la República y el Principado los jurisconsultos reúnen en sí la doble condición de juristas y profesores de Derecho, con claro predominio de las características históricas que configuran la primera función sobre la segunda.

La enseñanza del Derecho constituye una parcela mínima dentro de la actividad respondiente del jurista, cuya consideración era noble, rígidamente aristocrática. Los que se dedican a la actividad jurídica son ciudadanos de alta condición social, que prestan sus servicios gratuitamente, benificii loco, por espíritu de liberalidad. Tal servicio intelectual fue considerado por el pensamiento romano como un honor, como una obligación honorable, que excluía cualquier posible contraprestación por el servicio realizado. En una sociedad donde el trabajo remunerado fue considerado vil e indigno de un ciudadano romano, habría sido incompatible con la posición social del jurisconsulto aceptar remuneración por sus opiniones. Los juristas recibían como el mejor precio por su actividad el favor de sus conciudadanos: la popularidad, lo que les servirá para ocupar los mejores puestos políticos y sociales. Su elevada posición socio-económica y el hecho de percibir ingresos por su carrera política o administrativa, les permite mantener el carácter gratuito de sus consultas y lecciones.

La situación cambia en el Bajo Imperio, de una parte, el jurista clásico ha desaparecido, de otra parte, se desarrollan las instituciones de enseñanza superior. En este momento la conciencia social romana no encuentra ya objeción alguna para que los profesores de Derecho sean remunerados, ya que ahora no son considerados como jurisconsultos, sino como profesores.

En relación con la actividad docente, ya desde época antigua los romanos advirtieron la necesidad de que el conocimiento del Derecho debía basarse necesariamente en el estudio ordenado del sistema jurídico. Y, efectivamente, son los únicos, entre todos los pueblos antiguos, que elaboraron manuales elementales llamados institutiones, donde se exponen brevemente, de forma sencilla y fácil, según un orden y una distribución sistemática, los institutos de derecho privado, y se sintetizan principios generales, conceptos y definiciones.

El manual más antiguo del que tenemos noticia son los Libri tres iuris civilis del célebre jurista-maestro de derecho Masurio Sabino, que constituiría el texto-base de la escuela sabiniana. Pero sin duda alguna, la obra más importante de este tipo son las Institutiones de Gayo, que han llegado hasta nosotros casi al completo en un palimpsesto de la biblioteca capitular de Verona. La obra debió tener ya ab antiquo una grandísima importancia, siendo conocida en Oriente y Occidente, al ser el libro de texto para el primer curso de Derecho en las escuelas de Berito y Constantinopla. A pesar de no ser un jurista original, debía ser ampliamente conocido por los prácticos del Derecho, como se demuestra que en la llamada Ley de Citas, de Valentiniano III y Teodosio II, Gayo, que no había obtenido el ius publice respondendi, está colocado junto a Papiniano, Ulpiano, Paulo y Modestino. Las Instituciones de Gayo constituyen el manual sobre el cual toda Europa ha estudiado el derecho.

Otros juristas que escribieron libros dedicados a la enseñanza fueron Florentino, Pomponio, que escribió la única exposición sistemática de la historia del Derecho romano que conservamos, Marciano, Calistrato, Paulo o Ulpiano.

Junto a esta literatura elemental o didáctica, los jurisconsultos escribieron una abundante literatura jurídica que será estudiada por los futuros juristas en un nivel superior -instruere-. Dicha literatura jurídica puede ser catalogada en los siguientes apartados: a) Responsa: colecciones de respuestas dadas por un jurista a casos efectivamente formulados 
por un determinado consultor, que se presentaban agrupados por materias siguiendo el orden del edicto; b) Quaestiones o disputationes: colecciones de respuestas dadas por un jurista a casos imaginados, propuestos o sugeridos por los auditores; c) Digesta: colecciones amplias y sistematizadas según el edicto del pretor de quaestiones y responsa jurisprudenciales referentes a todo el derecho privado vigente; d) Libri ad edictum: comentarios sistemáticos realizados por los juristas al edicto pretorio y al edilicio; e) Libri singulares: comentarios jurisprudenciales referentes a distintas instituciones jurídicas como dote, tutela, testamentos, legados, etc.

\section{La enseñanza del Derecho en la Monarquía absoluta o Dominado}

El nuevo orden político que supuso el paso del Principado al Dominado trajo consigo, entre otros cambios, una nueva concepción de la cultura y consiguientemente de la enseñanza jurídica. Durante el Principado, la enseñanza del Derecho constituía una parcela más de la iniciativa privada del ciudadano romano, combinado con la inexistencia de toda clase de controles reglamentarios. La situación cambió durante el Dominado. En la parte oriental del Imperio la enseñanza del Derecho se ve sometida a la intervención imperial, que proporciona a los docentes lugares públicos donde desempeñar su oficio, se preocupa de asegurar la regularidad de sus salarios, abonados por el propio Estado y no por los padres $y$, por último, les otorga una serie de privilegios personales y fiscales.

En opinión de Cannata ${ }^{32}$, la jurisprudencia era la única disciplina ligada a una tradición plenamente romana, tanto por sus contenidos, su método, su lenguaje técnico, como por los modos de su enseñanza y las personas que la profesaban. Pero la enseñanza de la jurisprudencia no era una enseñanza escolar; incluso si no hubiera sido interrumpida antes de mediados del siglo III, nunca habría estado en condiciones de asegurar la formación de todos los operadores jurídicos que la burocracia tentacular del Imperio necesitaba. Sin embargo, en Oriente, se adoptaron medidas a tiempo para escolarizar la enseñanza del Derecho. En el Imperio de Oriente, caracterizado por su administración pública bien organizada, pronto se dieron cuenta de que, aunque la formación adquirida en las escuelas del trivium estaba provista de algunas nociones de derecho, sin embargo no proporcionaba una base cultural suficiente para las carreras administrativas y judiciales.

En Oriente el elevado nivel cultural afectó a la enseñanza del Derecho. Además de las escuelas de retórica en las que como en Occidente se enseñaba también Derecho, existieron escuelas dedicadas exclusivamente a los estudios jurídicos: las celebérrimas de Berito y de Constantinopla y las menos famosas e, incluso, menospreciadas en el siglo VI, de Alejandría, Antioquia de Siria, Gaza, Cesarea de Palestina y Atenas. Estos centros de estudios universitarios aseguraron la continuidad del conocimiento de la obra de los juristas clásicos no sólo educando a los estudiantes en la lectura de sus libros, sino también conservando los textos en sus ricas bibliotecas. La de Constantinopla, creada hacia el año 330, llegó a reunir unos cien mil volúmenes, y se repuso pronto, gracias a la protección del emperador Zenón, del incendio que la destruyó en el año 475. La biblioteca de Constantinopla gozará siempre del favor y cuidado imperial, como demuestra la iniciativa de Valentiniano I, del año 372, al contratar con cargo a fondos públicos a siete expertos copistas confiándoles la trascripción de los códices ya muy deteriorados en aquel tiempo ${ }^{33}$.

Como afirma Churruca ${ }^{34}$, las escuelas eran oficiales con plan de estudios fijo y profesores-funcionarios pagados por la administración pública. Los estudiantes pertenecían a las clases sociales superiores, se preparaban en general en la escuela para el desempeño

${ }^{32}$ CANNATA, Historia, cit., pp. $108 \mathrm{~s}$.

${ }^{33}$ C. Th. I4, 9, 2.

${ }^{34}$ CHURRUCA, Introducción histórica al Derecho romano (Bilbao I989) p. 227. 
de cargos públicos y pagaban tasas de enseñanza. No era una mera preparación práctica, sino una formación de orientación fundamentalmente teórica de alto nivel científico y tendencia marcadamente clasicista. Por ello en las escuelas dominó un profundo respeto por los autores clásicos y por sus textos, sin pretensiones de adaptarlos al derecho vigente o a las concepciones jurídicas tanto vulgares como regionales contrapuestas al clasicismo. Ese clasicismo hizo que los autores clásicos se estudiaran en la escuela con un espíritu muy distinto del de los autores estudiados: con ausencia de sentido práctico y con una metodología helenística con tendencia marcada a la sistemática, a la generalización de normas (formación de reglas generales) y a la creación y delimitación de conceptos (definiciones, distinciones, diferencias).

Escasa información poseemos sobre el plan de estudios de la Escuela jurídica de Berito con anterioridad al siglo V. Como afirma Collinet ${ }^{35}$, en los siglos II, III y IV la Escuela de Berito es ya célebre, pero desconocemos el programa y la duración de sus estudios. Suficiente información tenemos sobre el período de los maestros «ecuménicos»o «antiguos» a través del testimonio de Justiniano en su Constitutio Omnem, donde describe el plan de estudios de derecho tanto de Berito como de Constantinopla.

El plan de estudios que se imparte en estas Escuelas tiene una duración de cuatro años, y viene así distribuido:

El primer curso, los alumnos llamados por sus compañeros con el despectivo mote de «dupondii» ${ }^{36}$, estudian las Instituciones de Gayo más cuatro libros singulares relacionados con el derecho de familia y sucesiones: el primero, sobre la antigua acción dotal, el segundo, sobre las tutelas, el tercero, sobre los testamentos y el cuarto, sobre los legados. No se dice de qué autores sean, habiéndose atribuido a colecciones de textos de los Libri ad Sabinum de Paulo y de Ulpiano. En opinión de Archi ${ }^{37}$, se estudian las partes esenciales de la literatura civilista, mientras que en los restantes se abordarían las partes fundamentales del sistema edictal. Por tanto, a través del estudio de las materias del primer año, los alumnos adquieren un conocimiento de aquellas estructuras jurídicas sin las cuales no es posible entender la mayor parte del sistema edictal.

El segundo curso, los alumnos llamados edictales, estudian la Prima pars legum; y algunos títulos escogidos de la Pars de iudiciis y de la de rebus. La obra sobre la que se verificaría el estudio sería probablemente el gran comentario al Edicto de Ulpiano. Frezza ${ }^{38}$ considera plenamente coherente esta distribución, y añade que las dos partes, de iudiciis, y de rebus, cubren sin fisuras aquella distribución de las acciones en vindicationes y petitiones.

El tercer curso, los alumnos llamados papinianistas, en razón al estudio de este jurista, estudian los libros restantes sobre las cosas y los juicios, más ocho libros de las Respuestas de Papiniano, si bien desconocemos cuáles eran y desde luego no íntegros, sino muy abreviados o quizá más exactamente, mutilados.

El cuarto curso, los alumnos llamados lytae o los que resuelven casos o problemas jurídicos, estudian las respuestas de Paulo, privadamente, sin necesidad ya de profesor oficial, aunque con ayuda de profesores particulares.

\footnotetext{
${ }^{35}$ COLLINET, Histoire, cit., pp. 2I9 ss.

${ }^{36}$ Sobre la enigmática significación del término, vid. AGUDO RUIZ, La enseñanza, cit., p. 98 nt. 288.

${ }^{37}$ ARCHI, Giustiniano e l'insegnamento del diritto, en L'Imperatore Giustiniano, storia e mito (Milano I978) pp. II3 ss.

${ }^{38}$ FREZZA, Responsa e Quaestiones. Studio e politica del diritto dagli Antonini ai Severi, en SDHI, 43 (I977) p. 257.
} 
Llegados a este momento surge un problema importante consistente en determinar en qué forma se presentaban las obras de la jurisprudencia clásica a los alumnos y a los profesores. Para Collinet ${ }^{39}$, toda esta materia estaría recogida en seis libri o volumina. Estas obras jurisprudenciales estarían reproducidas extensamente y no por fragmentos, como sucederá en el Digesto. Sin embargo ni los profesores las explicarán ni los alumnos las estudiarán en su totalidad, pues tanto unos como otros siguen el malacostumbrado método de saltar por partes.

El quinto curso, de carácter facultativo, no obligatorio, los alumnos estudian por su cuenta las leges, es decir, las constituciones imperiales contenidas en los Códigos Gregoriano, Hermogeniano y Teodosiano, y las posteriores.

Como se observa, este plan de estudios adolece de una escasa atención al estudio del derecho vigente, relegado al último año de carrera, mientras que se pone especial atención en el adiestramiento del razonamiento jurídico, para el que ofrecía una base insuperable el material de las fuentes clásicas.

Al terminar los estudios, los alumnos tienen que superar un examen final para obtener el correspondiente diploma o certificado que acredite sus conocimientos jurídicos. Así se les exige a los abogados de la pars Orientis para poder ejercer la profesión forense ${ }^{40}$.

Durante los cinco años de duración de la carrera de Derecho, los estudiantes, pertenecientes a las clases sociales más elevadas, están exentos de la obligación de aceptar la tutela, según se afirma en Fragmenta Vaticana 240. Igualmente, Diocleciano exonera de los munera personalia a los estudiantes hasta la edad de los 25 años ${ }^{4 \mathrm{I}}$.

La época postclásica se caracteriza por una absoluta libertad de método y de contenido. Inicialmente el método de enseñanza era el practicado en las Stationes de Roma, una mezcla de enseñanza casuística, esto es, práctica, y enseñanza dogmática ${ }^{42}$. Más tarde, parece ser que en el siglo IV se comienza a emplear el método de la interpretatio, según se comprueba en la interpretatio Gai de Autun en el Fr. Vat. 76 y en otros lugares, método que consistía en poner al alcance de la mentalidad de los estudiantes de aquel tiempo las obras de los juristas clásicos ${ }^{43}$.

La enseñanza descansa en la figura profesional del magíster iuris, aunque dotado de una mayor formación intelectual que los de la parte occidental del Imperio. El profesor emplea un estilo directo y con constantes preguntas a sus alumnos con la finalidad de mantener su atención. Durante las explicaciones, los alumnos deben tomar apuntes. Estos apuntes son los que precisamente nos han permitido conocer la actividad pedagógica en las escuelas de Derecho.

Por otra parte, como afirma Churruca ${ }^{44}$, se explicaba el texto básico, omitiéndose a veces pasajes que no se consideraban de interés. En la explicación y exposición había diversos elementos formales que con frecuencia quedaban recogidos por escrito y a los que en términos generales se les daba la designación de glosas y escolios (scholia). Tales eran las proteorías (protheoriai) o breves introducciones al texto que a continuación se trataba, los

\footnotetext{
${ }^{39}$ COLLINET, Histoire, cit., pp. 229 ss.

${ }^{40}$ Sobre el tema, vid. AGUDO RUIZ, Abogacía y Abogados. Un estudio histórico-jurídico (Logroño-Zaragoza I997).

${ }^{41}$ C. J. IO, 50(49), I; 2.

${ }^{42}$ COLLINET, Histoire, cit., p. 243.

${ }^{43}$ COLLINET, Histoire, cit., p. 243; HERNÁNDEZ TEJERO, La enseñanza, cit., pp. I6r s.

${ }^{44}$ CHURRUCA, Introducción, cit., pp. $227 \mathrm{~s}$.
} 
índices o breves resúmenes de la materia tratada; las glosas o notas aclaratorias marginales o interlineales; la paráfrasis (paraphrasis) o exposición con otras palabras más sencillas del contenido del texto, las parágrafes (paragraphai) o breves comentarios y observaciones explicativas del texto; los paratitla (paratitla) o anotaciones complementarias con referencias a pasajes paralelos de otras obras en que se trataba la misma materia de manera más completa.

La enseñanza se imparte en griego, lengua ésta por lo demás que tanto los profesores como los alumnos conocían, mientras los textos mantuvieron su lengua original, el latín. Las lecciones se imparten todos los días de la semana, excepto el sábado por la tarde y el domingo. Se realiza por la tarde, así los alumnos utilizan las mañanas para el estudio y los profesores para compatibilizar la docencia con la abogacía. Los alumnos comienzan y terminan sus estudios jurídicos con el mismo profesor.

Frente al intervencionismo estatal que caracterizará la enseñanza del Derecho en el período justinianeo, la época postclásica se caracteriza por una absoluta libertad de método y de contenido. La única intervención estatal reside en la elección de los profesores públicos, fuera de este extremo, los docentes poseen una plena libertad de enseñar aquello que quieran y como quieran. El emperador no legisla para mermar la libertad de cátedra del docente oficial.

Hasta el siglo IV no existe ninguna fuente, jurídica o literaria, que nos permita conocer el sistema de elección de los profesores de Derecho. Una constitución del emperador Juliano el Apóstata del año 362 regula por primera vez la elección de los profesores que imparten una enseñanza pública ${ }^{45}$ : I) valoración de los méritos de los candidatos mediante concurso público denominado probatio, en el que aquellos presentan una muestra de sus conocimientos al juicio unánime de una comisión de notables optimorum conspirante consensu-; 2) nombramiento, mediante decreto, de la Curia municipal; 3) ratificación imperial de dicho nombramiento.

La ley escolar de Juliano supone un ataque directo contra los docentes cristianos, que viene confirmado por su epístola número 6r. Esta circular explicativa de la ley del 362 , representa el acto más anticristiano de Juliano dirigido contra los profesores cristianos, a los cuales, bajo la premisa de la coherencia entre la moral y la docencia, se les obliga a elegir entre su religión o su profesión.

La reforma general de los estudios superiores y, consiguientemente, la restauración de una escuela pagana que educase en los principios del politeísmo, en el sentido más tradicionalista de la institución universitaria, apenas duró dos años, pues por una constitución de los emperadores Valentiniano I y Valente, del año 364, los profesores cristianos vuelven a las aulas ${ }^{46}$.

Los profesores de Constantinopla, a partir del año 425, reciben un salario público del Estado similar al de los demás funcionarios estatales ${ }^{47}$. Es probable que los profesores de Berito reciban hacia la misma época el mismo tratamiento oficial. No sabemos, sin embargo, la cuantía del mismo, aunque cabe suponer que debía ser elevada, conforme a la posición social que en este período adquieren los docentes de la enseñanza pública superior. Los demás profesores de Derecho que imparten su docencia en otras escuelas jurídicas del Imperio, reciben un salario público de los municipios donde tienen su sede dichas escuelas.

\footnotetext{
${ }^{45}$ C. Th. I3, 3, 5 .

${ }^{46}$ C. Th. I3, 3, 6.

${ }^{47}$ C. Th. I4, 9, 3, I.
} 
Los titulares de una cátedra de Derecho están dispensados de la tutela y de la curatela. Teodosio II y Valentiniano III en el año 425 premian a los mejores profesores que al cabo de los veinte años de servicio constante y de entrega desinteresada han demostrado no sólo sus conocimientos sino también sus dotes pedagógicas con el título de condes de primera clase ${ }^{48}$.

\section{La enseñanza del Derecho en época de Justiniano.}

La existencia del Codex Iustinianus y la ya pronta publicación de la compilación de las obras de la jurisprudencia, digesta o pandectae, hacían necesaria una reforma del plan de estudios de Derecho para adaptarlo a los profundos cambios que se habían producido en las estructuras del derecho positivo. En efecto, como afirma Cannata ${ }^{49}$, Justiniano, o quizá más precisamente Triboniano y sus colaboradores, comprendieron que lo que la historia llamaría el Corpus Iuris Civilis no era una simple compilación, sino una profunda reforma del derecho. Habían operado una síntesis de la tradición clásica, de la legislación postclásica, de la práctica y de las concepciones de las escuelas de Oriente, y esta síntesis formaba una trama completamente nueva a la que el derecho positivo se encontraba anudado de ahora en adelante. Además, el nuevo soporte no podía darse a conocer con la colección de las constituciones ni con la de las obras de los juristas; evidentemente tampoco estaba presente en las antiguas síntesis institucionales.

Unos días después de la publicación de las Instituciones y en la misma fecha de la Constitución Tanta que promulgó el Digesto, Justiniano reforma el viejo plan de estudios universitario para adaptarlo a la nueva compilación a través de la Constitución Omnem del I6 de diciembre del año 533, dirigida a los ocho profesores más prestigiosos de la época de las Universidades de Berito y Constantinopla, al frente de los cuales figuran Teófilo -que moriría en Constantinopla en el 536- y Doroteo - profesor en la Escuela de Berito-; junto a éstos son mencionados Teodoro, Isidoro, Anatolio, Taleleo, Cratino y Salamino.

La nueva concepción del Derecho y, consiguientemente de su enseñanza, para ser comprendida en sus justos términos debe enmarcarse dentro de una amplia reforma constitucional de la cultura y de la organización jurídica del Estado romano. Justiniano cree que la ciencia del Derecho es reconducible a un sistema acabado del que es posible ofrecer a los estudiantes una exposición completa y cerrada.

Para $\mathrm{Archi}^{\text {50 }}$, en la concepción justinianea el derecho es una scientia, una legitima scientia, cuyo aprendizaje debe producirse siguiendo una exposición orgánica y racional y no desarticulada, fragmentaria y memorística. Puntualiza el mencionado autor la diferente concepción de la legitima scientia para los clásicos y para Justiniano. Para los primeros, el derecho clásico es ante todo derecho jurisprudencial y, consiguientemente, los propios juristas tienen conjuntamente la función creadora y docente. Para Justiniano, por el contrario, la scientia iuris es algo externo a los juristas; éstos la deben conocer, pero no es objeto de una actividad creadora en el sentido de los antiguos jurisconsultos, deben limitarse a enseñarla.

En esta línea de intervencionismo, Justiniano traza la actuación de los profesores indicándoles, por una parte, que las Instituciones deben ser explicadas en primer lugar, y por otra, que de los cincuenta libros que componen el Digesto basta tan sólo la explicación de treinta y seis de éstos ${ }^{5 \mathrm{~T}}$. Como observa $\mathrm{Archi}^{52}$, concebidos los Digesta como una collatio

\footnotetext{
${ }^{48}$ C. Th. 6, 2I, I.

${ }^{49}$ CANNATA, Historia, cit., p. I25.

${ }^{50}$ ARCHI, Giustiniano, cit., pp. I06 ss.

${ }^{51}$ Const. Omnem, pr. in fine.
} 
de todo el ius antiquum, en los arcana penetralia en los que los homines rudes no están en disposición de introducirse, las Institutiones tienen la función de dar a los estudiantes los totius legitimae scientiae prima elementa. Por tanto, desde el punto de vista didáctico, la secuencia establecida por Justiniano es lógica, las Institutiones tienen un carácter propedéutico a los Digesta.

A pesar del prestigio innegable que alcanzan los estudios jurídicos en las escuelas de Berito y Constantinopla, Justiniano se muestra muy crítico con dicha ordenación de los estudios y subraya las graves lagunas y las incongruencias de tal regulación que quedaban reducidas a papel mojado muchas veces por la imposibilidad de desarrollar los programas adecuadamente. Justiniano comienza resaltando que anteriormente, de toda la multitud de leyes que llenaban hasta dos mil libros, y hasta tres millones de líneas, los estudiantes oían a sus maestros tan sólo seis libros, poco claros y que raras veces contenían derecho de utilidad, y los otros, o habían caído en desuso o eran inaccesibles para todos. Critica que la lectura del texto no la realice el maestro de manera continua. Igualmente, critica la mezcla del ius utile con el ius inutiles3.

El nuevo plan de estudios que Justiniano diseña y establece en la Constitución Omnem (2-5) tiene una duración de cinco años y un preciso material de estudio, que naturalmente es su reciente Compilación. La materia viene así distribuida:

El primer año, los alumnos, que se llamarán en lo sucesivo «jóvenes justinianeos», estudian las Instituciones de Justiniano, más la parte llamada Prota, que contienen Principios generales sobre el derecho y la jurisdicción: son los libros De Iustitia et Iure, De iurisdictione, De postulando y De in integrum restitutionibus.

El segundo año, los alumnos, que se siguen llamando «edictales», en recuerdo a la obra de Ulpiano Libri ad Edictum, estudian los siete libros De iudiciis, o bien, los ocho libros De rebus, según lo permita, en cada caso, la duración del curso. Además estudian cuatro libros más: uno sobre tutela, uno sobre dote, uno sobre testamento y uno sobre legados y fideicomisos, dejando los otros diez para mejor momento, pues ni la duración del curso lo permite ni cabe una explicación detenida de estos catorce libros.

El tercer año, los alumnos se siguen llamando «papinianistas» en honor al gran Papiniano. Se completa el estudio De iudiciis o De rebus, en la forma que correspondiese según lo estudiado en el año anterior. Además estudian tres libri singulares: sobre la fórmula hipotecaria, sobre el edicto de los ediles y la acción redhibitoria respecto a la compraventa, y sobre la evicción y vicios ocultos. Se completa con el estudio de una selección de textos de Papiniano de sus Respuestas, Cuestiones y Definiciones.

El cuarto año, los alumnos se siguen llamando «resolvedores de casos». Estudian los restantes ro libri singulares del Digesto que son continuación de la parte de Familia y Sucesiones estudiada en el segundo año: donaciones entre cónyuges, testamentos, legados y fideicomisos.

Los estudiantes que hasta ahora han tenido al mismo profesor durante los cursos precedentes y para todas las materias, deben cursar un quinto año, quizá sin la obligación de asistir a clases regularmente, los alumnos se llaman «resolvedores avanzados». Estudian los últimos I4 libros del Digesto, que tratan sobre la posesión de los bienes hereditarios, denuncia de obra nueva, manumisiones, interdictos, estipulaciones, delitos, apelaciones, magistrados municipales, etc. Además, estudian el Código de Justiniano, desde el año 535, en su segunda y definitiva edición, y, las nuevas constituciones justinianeas según se

\footnotetext{
${ }^{52}$ ARCHI, Giustiniano, cit., p. IO4.

${ }^{53}$ Const. Omnem, I.
} 
fueron promulgando. Se obtendrá, así, una lectura casi total de las compilaciones justinianeas.

Justiniano, después de presentar su nuevo plan de estudios, expresa su firme convicción de que, con su estudio, los estudiantes no dejarán de conocer nada sobre la ciencia del Derecho, llegando a convertirse en excelentes abogados o en eficaces funcionarios ${ }^{54}$.

Convencido de la bondad de su obra, Justiniano controla también la actividad de los editores en la reproducción y divulgación de los libros de enseñanza, prohibiéndoles cualquier alteración, presente o futura, de sus libros, con la aplicación de la pena del crimen falsitatis, más la estimación del doble del valor del libro modificado y su imposibilidad de alegarlo como doctrina en un juicios.

Respecto a los estudiantes, además de mantener vigentes las inmunidades otorgadas por los Emperadores precedentes durante el tiempo que permanezcan cursando sus estudios. Impone la prohibición de «ludos exercere» en cuanto que las fiestas estudiantiles daban lugar con bastante frecuencia a verdaderos y propios «crimina», especialmente en las confrontaciones con los estudiantes de primer año. Advierte a los estudiantes que se abstengan de juegos indignos, serviles o injuriosos contra los profesores o sus propios compañeros, bajo la amenaza de severísimas penas ${ }^{56}$.

Como afirma Bonini57, en la Const. Omnem no se concede relieve, sin embargo, a la mayor dificultad de los estudios, que era la de naturaleza lingüística: la mayor parte de los estudiantes sólo conocía bien el griego, mientras grupos más restringidos, provenientes de las regiones latinas de Oriente, o incluso de Occidente, conocían, sin embargo, sólo el latín, encontrándose, por su parte, con dificultades con las constituciones griegas y en particular con las Novelas. De aquí, y no sólo por las exigencias de los ambientes de la práctica, la necesidad de preparar versiones y comentarios en griego, o viceversa, en latín, de los principales textos jurídicos.

Por último, el Emperador reduce los centros universitarios públicos autorizados para impartir los estudios jurídicos a Berito, Constantinopla y Roma ${ }^{58}$. Respecto al sistema de acceso de los profesores de Derecho a la enseñanza oficial, Justiniano mantiene la regulación establecida por Juliano el Apóstata (C. Th. I3, 3, 5), con la única diferencia de la eliminación del requisito de la ratificación imperial ${ }^{59}$. Todos los profesores que imparten su docencia en las universidades estatales tienen derecho a percibir un salario público ${ }^{60}$. Igualmente ratifica todos los privilegios otorgados por emperadores precedentes, extendiéndolos a sus esposas, hijos y bienes, insertándolos en la noble imperial.

\footnotetext{
${ }^{54}$ Const. Omnem, 6.

${ }^{55}$ Const. Omnem, 8. Sobre el alcance de estas prohibiciones, vid. BERGER, The Emperor Justinian's Ban upon Commentaries to the Digest, en BIDR, 55-56 (I95I) pp. 158 ss.

${ }^{56}$ Const. Omnem, 9 y iо.

${ }^{57}$ BONINI, Introducción al estudio de la edad justinianea, trad. esp. Álvarez de Cienfuegos (Granada I979) p. 70.

${ }^{58}$ Const. Omnem, 7 .

${ }^{59}$ C. J. IO, 53(52), 7 pr.

${ }^{60}$ C. J. IO, 37(36), I.
} 


\section{Bibliografía}

\section{V.r Fuentes}

C.J.; C. I. Codex Iustinianus. Corpus iuris civilis, vol. II, ed. Krüger, Berlin, I954.

Coll. Collatio legum mosaicarum et romanarum, F.I.R.A., I.

C. Th. Codex Theodosianus, ed. T. Mommsen-Meyer, Berlin, I954.

D. Digesta. Corpus iuris civilis, vol. I, ed. Mommsen-Krüger, Berlin, I954.

Ed. Edictum.

Inst. Institutiones Iustiniani. Corpus iuris civilis, I, ed. P. Krüger, Berlin, I954.

Palingenesia Palingenesia Iuris Civilis, Lenel.

Tácito Annales, Oxford, I963.

Ulp. Tituli ex corpore Ulpiani, F.I.R.A., II.

V.I.R. Vocabularium Iurisprudentiae Romanae.

\section{V.2 Revistas y colecciones de escritos}

A. Cat. Annali del Seminario giuridico della Università di Catania.

A. Cos. Atti della Accademia Romanistica Costantiniana. Perugia.

A.G.

Archivio giuridico «Filippo Serafini», Bologna-Pisa. Desde I92I, Módena.

A.H.D.E.

Anuario de Historia del Derecho Español, Madrid.

A.H.D.O.-R.I.D.A.

Archives d'histoire du droit oriental-Revue internationale des droits de l'antiquitè, Bruxelles.

A.J.Ph. The American Journal of Philology, Baltimore.

A. Nap.

Atti della Accademia di Scienza morali e politiche di Nàpoli.

A. Per.

Annali della Facoltà di Giurisprudenza della Università di

Perugia.

A.U.P.A. Annali della Università di Palermo.

B.I.D.R. Bulletino dell'Istituto di Diritto Romano, Milano.

D.I. Digesto Italiano.

D.S. Daremberg-Saglio. Dictionnaire des antiquitès grecques et romaines.

E.D.

Enciclopedia del Diritto, Milano.

I.N.D.E.X.

Index. Quaderni camerti di studi romanistici, Nàpoli.

I.U.R.A.

Rivista internazionale di diritto romano e antico, Nàpoli.

Labeo

Labeo: Rassegna di Diritto romano, Nàpoli.

Mél. Girard

Mélanges P. F. Girard, 2 vols., Paris, I9I2.

N.N.D.I.

Novissimo Digesto Italiano.

P.W.

Paulys Realenzyklopädie der Klassisch G. Wissowa, Kroll, Mittelhans, Ziegler, Stuttgart. 
R.H.

R.I.D.A.

R.I.S.G.

Scr. Jemolo

S.D.H.I.

Sodalitas

St. Albertoni

St. Arangio-Ruiz

St. Besta

St. Betti

St. Biondi

St. Biscardi

St. Bonfante

St. De Sarlo

St. Grosso

St. Polay

St. SanFilippo

St. Scaduto

St. Schiller

St. Thomas

St. Vassalli

St. Volterra

Synteleia

Z.S.S.
Revue Historique de Droit Français et Étranger, Paris.

Revue Internationale des Droits de l'Antiquité, Bruxelles.

Rivista Italiana per la Scienze Giuridiche, Milano.

Scritti in onore di A. C. Jemolo, vol. 4, Milano, I963.

Studia et Documenta Historiae et Iuris, Roma.

Scritti in onore di A. Guarino, 9 vols., Nàpoli, I984.

Studi in memoria di A. Albertoni, I, Padova, I934; II,

I937; III, I938.

Studi in onore di V. Arangio-Ruiz, 4 vols., Nàpoli, I953.

Studi di storia e di diritto in onore di E. Besta, per il XL annno del suo insegnamento, 4 vols., Milano, I937-I939.

Studi in onore di E. Betti, 5 vols., Milano, I962.

Studi in onore di B. Biondi, 4 vols., Milano, I965.

Studi in onore di A. Biscardi, 6 vols., Milano, I982-I983.

Studi in onore di P. Bonfante, 4 vols., Milano, I930.

Studi in onore di L. De Sarlo, Milano, I989.

Studi in onore di G. Grosso, 6 vols., Torino, I968-I974.

Studia in honorem E. Polay, Szeged, I985.

Sudi in onore di C. SanFilippo, 7 vols., Milano I982-I983.

Studi in onore di G. Scaduto, vol. III; Diritto civile e

Diritto romano, Padova, I970.

Studies in memory of A.A. Schiller, Leiden, I986.

Studi in memory of J.A.C. Thomas, London, I983.

Stui giuridici in memoria di F. Vassalli, 2 vols., Torino I960.

Studi in onore di E. Volterra, 6 vols., Milano, I97I.

Synteleia V. Arangio-Ruiz, 2 vols., Nàpoli, I964.

eitschrift der Savigny-Stiftung für Rechtsgeschichte,

Romanist. Abt., Weimar. 